\title{
Pathological Worry is Related to Poor Long-Term Pharmacological Treatment Response in Patients With Panic Disorder
}

\author{
Hyun-Ju Kim" ${ }^{1 *}$, Ji Eun Kim²*, and Sang-Hyuk Lee ${ }^{1,3 凶}$ \\ ${ }^{1}$ Department of Psychiatry, CHA Bundang Medical Center, CHA University School of Medicine, Seongnam, Republic of Korea \\ ${ }^{2}$ Graduate School of Social Welfare, Yonsei University, Seoul, Republic of Korea \\ ${ }^{3}$ Department of Clinical Pharmacology and Therapeutics, CHA Bundang Medical Center, CHA University School of Medicine, Seongnam, \\ Republic of Korea
}

Objective Several predictors of unfavorable pharmacological treatment response (PTR) in panic disorder (PD) patients have been suggested, such as the duration of the illness, presence of agoraphobia, depression, being a woman, and early trauma. This study aimed to examine whether pathological worry is associated with PTR in PD patients.

Methods This study included 335 PD patients and 418 healthy controls (HCs). The Penn State Worry Questionnaire (PSWQ), the Early Trauma Inventory Self Report-Short Form (ETISR-SF), Beck Depression Inventory (BDI), Panic Disorder Severity Scale (PDSS), and Anxiety Sensitivity Inventory-Revised (ASI-R) were administered. We measured the PTR at 8 weeks and 6 months. Student t-test, chisquare tests, Pearson's correlation analyses, and binary logistic regression model were used.

Results Our results showed that the total scores of the PSWQ correlated with the ETISR-SF, BDI, and ASI-R were significantly higher in patients with PD compared with HCs. The PSWQ and BDI could predict unfavorable PTR at 6 months in PD patients.

Conclusion This is the first study to demonstrate that pathological worry may contribute to poor long-term PTR in PD patients. Therefore, our research suggests that clinicians must be aware of worry to optimize PTR for PD patients.

Psychiatry Investig 2021;18(9):904-912

Keywords Panic disorder; Pathological worry; Penn State Worry Questionnaire; Pharmacotherapy; Treatment response.

\section{INTRODUCTION}

Generally, worry, which is defined as "a chain of thoughts and images, negatively affect-laden and relatively uncontrollable," is a cognitive characteristic of anxiety that can be seen in normal individuals. ${ }^{1}$ In contrast, excessive worry is the cognitive component of anxiety and is closely associated with anxious apprehension, which may be an attempt at coping with unfavorable events. ${ }^{2}$

Panic disorder (PD) is an anxiety disorder whose main symptoms are recurrent and unexpected panic attacks, excessive wor-

\section{Received: July 8, 2021 Revised: July 12, 2021} Accepted: July 19, 2021

$\triangle$ Correspondence: Sang-Hyuk Lee, MD, PhD

Department of Psychiatry, CHA Bundang Medical Center, CHA University School of Medicine, 59 Yatap-ro, Bundang-gu, Seongnam 13496, Republic of Korea

Tel: +82-31-780-5694, Fax: +82-31-780-5862, E-mail: drshlee@cha.ac.kr

*These authors contributed equally to this work.

(a) This is an Open Access article distributed under the terms of the Creative Commons Attribution Non-Commercial License (https://creativecommons.org/licenses/by$\mathrm{nc} / 4.0$ ) which permits unrestricted non-commercial use, distribution, and reproduction in any medium, provided the original work is properly cited. ry about future panic attacks, and physical symptoms such as the sensation of shortness of breath, palpitation, and fear of dying. ${ }^{3}$ In particular, excessive worry in PD consists of persistent concern or worry about the implications of a panic attack or its consequences such as losing control and having a heart attack, with a tendency to cause considerable distress and functional impairment. Therefore, in patients with PD, excessive worry is might be explained "trait worry" more than "state worry," which is named pathological worry. ${ }^{4}$ In particular, the contents of pathological worry in PD differs from excessive worry about various events or activities in generalized anxiety disorder (GAD). ${ }^{3}$ However, patients with PD similar to GAD who experience pathological worry may tend to be focused on future negative outcomes that are vague in nature, resulting in problem generation rather than problem resolution. ${ }^{5}$

To reduce symptoms like pathological worry in patients with $\mathrm{PD}$, pharmacological treatment and second wave cognitivebehavioral therapy (CBT) have been well-established so far as effective methods. ${ }^{6-9}$ In addition, previous research has shown that pharmacotherapy is effective in reducing pathological wor- 
ry symptoms in patients with GAD.${ }^{10}$ However, diagnostic comorbidities such as anxiety disorders in patients with GAD having pathological worry is associated with lack of recovery. ${ }^{11}$ Furthermore, in clinical settings, even when such patients with PD are treated, the pharmacological treatment response (PTR) may not be quite satisfactory because approximately $20 \%-40 \%$ of patients with PD are non-responsive to pharmacotherapy with antidepressants such as selective serotonin reuptake inhibitors (SSRIs), serotonin-norepinephrine reuptake inhibitors, tricyclic antidepressants, and anxiolytics. ${ }^{12,13}$ In some clinical trials in which patients with PD were treated with SSRIs and anxiolytics for a period of 8 to 12 weeks, but $17 \%-61 \%$ of PD patients didn't respond to pharmacotherapy. ${ }^{14,15}$ Therefore, it is important to early detect patients with PD having pathological worry in advance so that other different alternative treatments can be considered for each patient. Moreover, further studies are needed to identify additional predictors of pharmacological treatment for patients with PD.

Several baseline predictors that could contribute to the PTR in patients with PD have been suggested. Previous short-term as well as long-term research has suggested several predictors in PD such as duration of the illness, the symptom severities of $\mathrm{PD}$, presence of agoraphobia, comorbidities with other psychiatric disorders including depressive disorders and personality disorders, and the female gender. ${ }^{16-22}$ In addition, some studies have found that recent emergency room visits and medical comorbidities in PD were might be predictors of poor PTR in patients with PD. ${ }^{23}$ Another study found an correlation between early sexual trauma and neuroticism, and unfavorable longterm PTR in patients with PD. ${ }^{24}$ However, few studies thus far have determined whether pathological worry is a predictor of PTR in PD. Further research about long-term pharmacotherapy needs to be done due to the lack of studies on the responses to long-term pharmacological treatment for pathological worry.

Our study addresses this gap in the literature by examining whether pathological worries are associated with long-term PTR in patients with PD using a relatively larger sample size than those used in previous studies. We hypothesized that patients with PD who experience pathological worry will have an unfavorable response to pharmacological treatments in longterm follow-ups.

\section{METHODS}

\section{Participants}

Between 2011 and 2021, 335 patients with PD and 418 healthy controls (HCs) participated in this study. We recruited participants from patients with PD who were treated in the Department of Psychiatry at CHA Bundang Medical Center. All participants were Koreans aged between 18 and 70 years old. The participants' family histories of PD were established through interviews. Participants with PD with or without agoraphobia met the DSM-IV-TR Axis I Disorder, as diagnosed by trained psychiatrists using the Structured Clinical Interview for DSMIV-TR. Although DSM-5 was published in 2013, we recruited patients with PD with the previous criterion, DSM-IV-TR, to collect data on a consistent basis from 2011 to 2021. Only patients primarily diagnosed as experiencing PD were included, and $\mathrm{PD}$ patients with additional major medical comorbidities were excluded. In addition, PD patients who followed up to 6 months after pharmacotherapy were included.

Participants with a primary diagnosis of any schizophrenia spectrum disorders, bipolar disorders, depressive disorders, anxiety disorders including $\mathrm{GAD}$ other than $\mathrm{PD}$, substance use disorders, personality disorder, mental retardation, major medical disorders including neurological disorders, and pregnancy were excluded. Furthermore, all patients with PD who had been treated with individual or group psychotherapy such as mindfulness-based cognitive therapy or CBT were excluded. In addition to, $\mathrm{HCs}$ with a history of psychiatric disorders were excluded.

All patients with PD had pharmacotherapy with SSRIs such as escitalopram, paroxetine, and sertraline (escitalopram equivalence dosage $=9.97 \pm 7.50[$ mean $\pm \mathrm{SD}] \mathrm{mg} /$ day $),{ }^{25}$ and BDZs including alprazolam, clonazepam, and diazepam were primarily permitted on a pro re nata (PRN; as required) basis. Some patients with PD were undergoing pharmacological treatment with antidepressants and anxiolytics according to the Korean Mediation Algorithm for $\mathrm{PD}^{26}$ or the Clinical Practice Guidelines: Treatment of PD. ${ }^{27}$ When analyzing several factors for the PTR in PD, interview and clinical assessments were performed during patients' first visit to the hospital. Participants were administered all self-report scales on the same day to rule out memory recall bias after medication commencement.

All study procedures complied with to the Institutional Review Board regulations and principles of Good Clinical Practice at the CHA Bundang Medical Center. After participants were provided with an enough explanation of the study process, methods, and purpose, their written informed consent was obtained.

\section{Clinical assessments}

\section{Penn State Worry Questionnaire}

To evaluate pathological worry in patients with PD in clinical settings, the Penn State Worry Questionnaire (PSWQ) is used. ${ }^{28}$ The PSWQ consisting of 16-item is made to assess the generality, excessiveness, and uncontrollability of pathological worry. Items of this inventory are rated on a 1-5-point scale and are known to have high internal consistency and excellent test- 
retest reliability. In this study, we also used the Korean version of the PSWQ, ${ }^{29}$ which represented high internal consistency (Cronbach's alpha: 0.952).

\section{Other clinical assessments}

Early trauma was evaluated using the Korean version of the Early Trauma Inventory Self Report-Short Form (ETISR-SF) with a Cronbach's $\alpha$ of 0.869 . ETISR-SF is significantly positively associated with the scores on the Childhood Trauma Questionnaire-Short Form ( $\mathrm{r}=0.691),{ }^{30}$ which consists of 27 "yes" or "no" questions in total evaluating the four domains of general, physical, emotional, and sexual trauma histories before the age of 18 years. In addition, each of the domains is evaluated using 11, 5, 5, and 6 questions, respectively.

The Korean version of the Anxiety Sensitivity Inventory-Revised (ASI-R) to assess potential anxiety trait markers in patients with PD at baseline. ${ }^{31,32}$ The ASI-R is the most commonly performed measure of anxiety sensitivity (AS), consisting of fears of respiratory symptoms, publicly observable anxiety reactions, cardiovascular symptoms, and cognitive dyscontrol.

To measure the clinical severity of the participants' anxiety and depressive symptoms at baseline in PD, we performed the Panic Disorder Severity Scale (PDSS) ${ }^{33}$ and the Beck Depression Inventory (BDI), ${ }^{34}$ respectively.

The PTR was evaluated after a minimum of 8 weeks and 6 months of pharmacotherapy in an adequate dose. It was defined as a total PDSS score reduction of $40 \%$ or more from the baseline score after 8 weeks and 6 months of treatment in an adequate dose..$^{35-37}$

\section{Statistical analyses}

To analyze the sociodemographic characteristics and clinical symptom severities including the PSWQ of patients with PD and HCs, the Student t-test and chi-square tests were performed.

In addition, Pearson's correlation analyses were applied to determine whether an association existed among continuous variables such as age, ETISR-SF, ASI-R, BDI, PDSS, and PSWQ at baseline.

Further, a binary logistic regression model with treatment response as the dependent variable and with those that can influence the treatment response at 8 weeks and in 6 months as covariates was performed in PD. All statistical analyses used the IBD SPSS Statistics 26.0 software (IBM Corp., Armonk, NY, USA). All reported probability values were two-tailed where $\mathrm{p}<0.05$ was considered statistically significant.

\section{RESULTS}

\section{Sociodemographic and clinical characteristics}

The sociodemographic and clinical characteristics of all study participants are summarized in Table 1. There were no significant differences between patients with PD and HCs in terms of age and gender at baseline. However, patients with PD had significantly lower levels of education than $\mathrm{HCs}\left(\chi^{2}=90.12, \mathrm{p}<\right.$ 0.001). Also, patients with PD were relatively less likely to live without a partner $\left(\chi^{2}=5.98, \mathrm{p}=0.014\right)$, and their monthly incomes were relatively lower than those of HCs $\left(\chi^{2}=9.10, \mathrm{p}=\right.$ 0.003). All clinical scale scores such as ETISR-SF (e.g., total sum, general, emotional, and sexual subtypes), ASI-R (e.g., total sum, all subtypes), and BDI at baseline were significantly higher in patients with PD compared with HCs $(\mathrm{p}<0.01)$. Over time, the total scores of PDSS in patients with PD gradually decreased from $12.33( \pm 6.33)$ (mean $[ \pm S D])$ at baseline to $9.89( \pm 5.01)$ at 8 weeks, then $8.85( \pm 4.77)$ at 6 months.

\section{Comparison of pathological worry between patients with panic disorder and healthy controls}

The total scores of the PSWQ at baseline were significantly higher in patients with PD compared with HCs PD: 52.73 $( \pm 12.68)$ (mean $[ \pm S D]), H C s: 38.64( \pm 9.14), t=14.14, p<0.001\}$ (Table 2). The result remained the same after the ANCOVA analysis controlling for education levels, marital status, and monthly income.

\section{Association between pathological worry and categorical variables in each panic disorder and healthy control group}

The mean PSWQ scores of patients with PD did not significantly differ by gender, level of education, monthly income, and marital status (all, $\mathrm{p}>0.05$ ). Furthermore, there was no statistical difference in the mean PSWQ scores by gender, level of education, and marital status in HCs (all, $\mathrm{p}>0.05$ ). However, in HCs, the mean PSWQ scores differed significantly in monthly income levels, and the lower the monthly income, the higher the PSWQ scores (Fisher's exact test, $\mathrm{p}=0.01$ ).

\section{Pearson's correlation analyses among continuous variables in healthy controls and patients with panic disorder}

Table 2 presents the correlations among continuous variables in HCs. The total scores of the PSWQ at baseline presented significant positive associations with the total sum of all subtypes ETISR-SF, emotional early trauma scores, sexual early trauma scores, ASI-R, and BDI at baseline among HCs $(\mathrm{p}<0.05)$. However, there was a significant negative correlation between the PSWQ scores at baseline and age $(\mathrm{p}<0.05)$.

In patients with PD, the total PSWQ scores at baseline showed significantly positive correlations with the total sum of all subtypes of ETISR-SF, the emotional early trauma scores, ASI-R, BDI, and PDSS at baseline, at 8 weeks, and 6 months (all, $\mathrm{p}<$ 
Table 1. Socio-demographic and clinical characteristics of patients with panic disorder and healthy controls

\begin{tabular}{|c|c|c|c|c|}
\hline & $\mathrm{PD}(\mathrm{N}=335)$ & $\mathrm{HCs}(\mathrm{N}=418)$ & Statistics $\left(\mathrm{t}\right.$ or $\left.\chi^{2}\right)$ & $\mathrm{p}$-value \\
\hline Age at baseline (years, mean $\pm \mathrm{SD}$ ) & $37.91 \pm 11.41$ & $36.84 \pm 11.31$ & 1.29 & 0.199 \\
\hline Gender (male [\%]/female) & $149(44.5) / 186$ & $195(46.7) / 223$ & 0.35 & 0.552 \\
\hline Years of education (high school or less [\%]/college or more) & $174(53.0) / 154$ & $76(19.3) / 318$ & 90.12 & $<0.001^{* * *}$ \\
\hline Marital status (living without partner [\%]/with partner) & $136(41.1) / 195$ & $190(50.3) / 188$ & 5.98 & $0.014^{*}$ \\
\hline Monthly income (below 1,800 \$USD [\%]/above 1,800 \$USD) & $33(10.2) / 290$ & $14(4.2) / 322$ & 9.10 & $0.003^{* *}$ \\
\hline Agoraphobia, yes (\%) & $242(73.8)$ & - & - & - \\
\hline Duration of illness (months, mean \pm SD) & $56.05 \pm 43.61$ & - & - & - \\
\hline Baseline ETISR-SF total score (mean \pm SD) & $4.96 \pm 4.00$ & $3.28 \pm 3.01$ & 4.04 & $<0.001^{* * *}$ \\
\hline General trauma sub-scale score & $1.34 \pm 1.49$ & $0.89 \pm 1.15$ & 2.89 & $<0.001^{* * *}$ \\
\hline Physical trauma sub-scale score & $1.89 \pm 1.62$ & $1.58 \pm 1.65$ & 1.63 & 0.104 \\
\hline Emotional trauma sub-scale score & $1.37 \pm 1.69$ & $0.66 \pm 1.19$ & 4.21 & $<0.001^{* * *}$ \\
\hline Sexual trauma sub-scale score & $0.39 \pm 0.88$ & $0.16 \pm 0.41$ & 2.95 & $0.001^{* *}$ \\
\hline Baseline ASI- $\mathrm{R}$ total score (mean $\pm \mathrm{SD})$ & $52.03 \pm 29.79$ & $8.23 \pm 10.47$ & 24.76 & $<0.001^{* * *}$ \\
\hline Fear of respiratory symptom & $19.76 \pm 11.80$ & $1.51 \pm 2.82$ & 27.24 & $<0.001^{* * *}$ \\
\hline Fear of cardiovascular symptom & $14.14 \pm 9.74$ & $2.80 \pm 4.98$ & 18.98 & $<0.001^{* * *}$ \\
\hline Fear of publicly observable anxiety reaction & $11.06 \pm 7.54$ & $3.35 \pm 4.27$ & 16.39 & $<0.001^{* * *}$ \\
\hline Fear of cognitive dyscontrol & $6.99 \pm 6.97$ & $0.84 \pm 1.76$ & 15.58 & $<0.001^{* * *}$ \\
\hline Baseline BDI total score (mean $\pm \mathrm{SD})$ & $17.77 \pm 10.83$ & $6.05 \pm 6.28$ & 17.32 & $<0.001^{* * *}$ \\
\hline PDSS total score at baseline (mean \pm SD) & $12.33 \pm 6.33$ & - & - & - \\
\hline PDSS total score at 8 weeks (mean \pm SD) & $9.89 \pm 5.01$ & - & - & - \\
\hline PDSS total score at 6 months (mean \pm SD) & $8.85 \pm 4.77$ & - & - & - \\
\hline Pharmacotherapy, yes (\%) & $244(72.8)$ & & & \\
\hline Kinds of SSRI \{escitalopram (N [\%])/paroxetine (N [\%])\} & $71(29.1) / 149(61.1)$ & - & - & - \\
\hline SSRI equivalent dosage $(\mathrm{mg}, \text { mean } \pm \mathrm{SD})^{\dagger}$ & $9.97 \pm 7.50$ & - & - & - \\
\hline
\end{tabular}

${ }^{*} \mathrm{p}<0.05 ;{ }^{* *} \mathrm{p}<0.01 ;{ }^{* * *} \mathrm{p}<0.001$; the approximate equivalent oral doses to $10 \mathrm{mg}$ Escitalopram are given. PD, panic disorder; HCs, healthy controls; ETISR-SF, Early Trauma Inventory Self Report-Short Form; ASI-R, Anxiety Sensitivity Inventory-Revised; BDI, Beck Depression Inventory; PDSS, Panic Disorder Severity Scale; SSRI, Selective Serotonin Re-uptake Inhibitor

0.001). However, there were significant negative associations between the PSWQ scores at baseline and age $(\mathrm{p}<0.01)$ (Table 3).

\section{Binary logistic regression analysis predicting the pharmacological treatment response at 6 months in patients with panic disorder}

To evaluate which factors contributed to the response of pharmacological treatment at 6 months, a binary logistic regression analysis was performed (Table 4 ). This model only included the essential variables (i.e., age, gender, education level, marital status, monthly income, PSWQ, BDI, PDSS, ASI-R, and early trauma at baseline).

After 6 months, the PSWQ at baseline $(B=-0.072, \mathrm{p}=0.018)$ and $\mathrm{BDI}(\mathrm{B}=-0.089, \mathrm{p}=0.047)$ were significantly negatively associated with the response of pharmacological treatment in patients with PD. In particular, higher total scores of PSWQ reduced the possibility of PTR in 6 months (OR=0.930, 95\% $\mathrm{CI}=0.876-0.988)$. However, the monthly income and the total score of PDSS at baseline were positively significantly associated with the PTR in patients with PD in 6 months. Higher PDSS scores were associated with a significantly better PTR in 6 months $(\mathrm{OR}=0.284,95 \% \mathrm{CI}=1.158-1.524)$.

This research model proved to be significant at $\mathrm{p}<0.05$, with the $\chi^{2}$ value for the $-2 \log$ likelihood difference between the null model in which the independent variable was excluded, and these models with the independent variable. The explanatory powers of these models at 6 months were $30.5 \%$ based on the Cox and Snell's $\mathrm{R}^{2}$, and overall percentage was $67.8 \%$.

\section{DISCUSSION}

This is the first study to demonstrate that pathological worry can influence the poor long-term PTR in patients with PD. The findings of our study suggest that patients with PD with pathological worry are more vulnerable and show more severe symptoms, which may lead to a chronic course of illness. There- 
Table 2. Pearson's correlations among continuous variables in healthy controls

\begin{tabular}{|c|c|c|c|c|c|c|c|c|c|}
\hline Continuous variables & 1 & 2 & 3 & 4 & 5 & 6 & 7 & 8 & 9 \\
\hline${ }^{1}$ PSWQ at baseline & - & & & & & & & & \\
\hline${ }^{2}$ Age & $-0.181^{*}$ & - & & & & & & & \\
\hline \multicolumn{10}{|l|}{ ETISR-SF } \\
\hline${ }^{3}$ Total sum of all subtypes & $0.179^{*}$ & -0.034 & - & & & & & & \\
\hline${ }^{4}$ General & -0.080 & $0.160^{*}$ & $0.647^{* *}$ & - & & & & & \\
\hline${ }^{5}$ Physical & 0.075 & -0.069 & $0.795^{* *}$ & $0.275^{* *}$ & - & & & & \\
\hline${ }^{6}$ Emotional & $0.367^{* *}$ & -0.125 & $0.673^{* *}$ & $0.213^{* *}$ & $0.292^{* *}$ & - & & & \\
\hline${ }^{7}$ Sexual & $0.179^{*}$ & -0.056 & $0.381^{* *}$ & $0.208^{* *}$ & 0.141 & $0.221^{* *}$ & - & & \\
\hline${ }^{8}$ ASI-R at baseline & $0.324^{* *}$ & 0.017 & $0.218^{*}$ & 0.133 & 0.096 & $0.255^{* *}$ & 0.037 & - & \\
\hline${ }^{9} \mathrm{BDI}$ at baseline & $0.472^{* *}$ & 0.072 & $0.326^{* *}$ & $0.176^{*}$ & 0.137 & $0.416^{* *}$ & 0.142 & $0.370^{* *}$ & - \\
\hline
\end{tabular}

${ }^{*} \mathrm{p}<0.05 ;{ }^{* *} \mathrm{p}<0.01$. PSWQ, Penn State Worry Questionnaire; ETISR-SF, Early Trauma Inventory Self Report-Short Form; ASI-R, Anxiety Sensitivity Index-Revised; BDI, Beck Depression Inventory

fore, our study shows that it is important for clinicians to check for these features at an early stage in patients with PD in initial interviews and to choose appropriate treatments for such individuals.

Previous studies showed the several risk factors contributing to worse PTR of patients with PD. ${ }^{16,18,19,21}$ In addition, our study showed that pathological worries affect long-term poor PTR in patients with PD. It is not clear why this occurs, but a neurobiological study showed that pathological worries were positively significantly correlated to the both medial orbitofrontal cortex (mOFC) volume playing a role in emotional decision-making under uncertain conditions in patients with GAD $(\mathrm{p}<0.001){ }^{38,39}$ Also, previous studies about PD have consistently reported volume reductions in mOFC. ${ }^{40,41}$ The OFC related to pathological worry contributes to preservative and inflexible thoughts and behaviors, and pathological worries suggest that repetitive nonreinforced thoughts and behaviors might be over-engaged when attempting to solve problems. Therefore, in patients with PD with pathological worries, maladaptive coping strategies related to the inability to activate a switch-off mechanism for fear might be reinforced, aggravating PTR.

From a psychological perspective, pathological worry is associated with coping strategies such as attempts to avoid negative events, interpersonal control, and cognitive failures. In the cognitive model of worry process presented by Eysenck, ${ }^{42}$ worry has three major functions: alarm, prompt, and preparation. In particular, the prompt function brings threat-related negative thoughts. The preparation function permits individuals to anticipate negative anticipatory scenarios in the future and to act with inappropriate coping strategies to prevent the anticipated negative events such as panic attacks, which makes the worry continue.

Our findings have shown a positive association between path- ological worry and secondary depressive symptoms. In addition, it has shown that the severity of secondary depressive symptoms in PD were correlated with unfavorable long-term treatment responses, although we excluded participants with primary major depressive disorder consistent with prior literature. ${ }^{18,43-46} \mathrm{~Pa}$ tients with secondary depression might have an earlier age at onset their panic symptoms and appeared to be more agitated, according to a previous study. ${ }^{47}$ As a result, patients with PD with severe secondary depression might be more likely to suffer from maladaptive patterns of their behaviors and thoughts, which is associated with responses to pharmacological treatment at long-term follow-ups.

In addition, our findings have shown that high symptom severity of $\mathrm{PD}$ at baseline in patients with $\mathrm{PD}$ was associated with good long-term PTRs inconsistent with prior literature. ${ }^{44}$ It is unclear why high PDSS scores were related to better PTR in our findings. However, we assume that the participants whose high symptom severity scores at baseline and decreased scores rapidly over time may have been included in our study. Because we recruited patients with $\mathrm{PD}$ in the acute care hospital equipped with an emergency room, this environment might have affected the PTR in our study.

Furthermore, we found that the AS associated with pathological worry in patients with PD does not significantly directly influence the PTRs at long-term follow-ups. Previous studies have suggested AS as a predictor of panic-related pathology, which may affect the frequency of panic attacks.8-50 Although AS is significantly positively associated with pathological wor$\mathrm{ry}^{51}$ and increases the level of symptom severities, it is unknown whether it has a direct relationship with the unfavorable longterm PTR. Therefore, further studies are needed to examine whether AS directly contributes to long-term poor PTR.

Notably, previous studies showed an correlation between early trauma and the frequency of panic attacks or the age of 


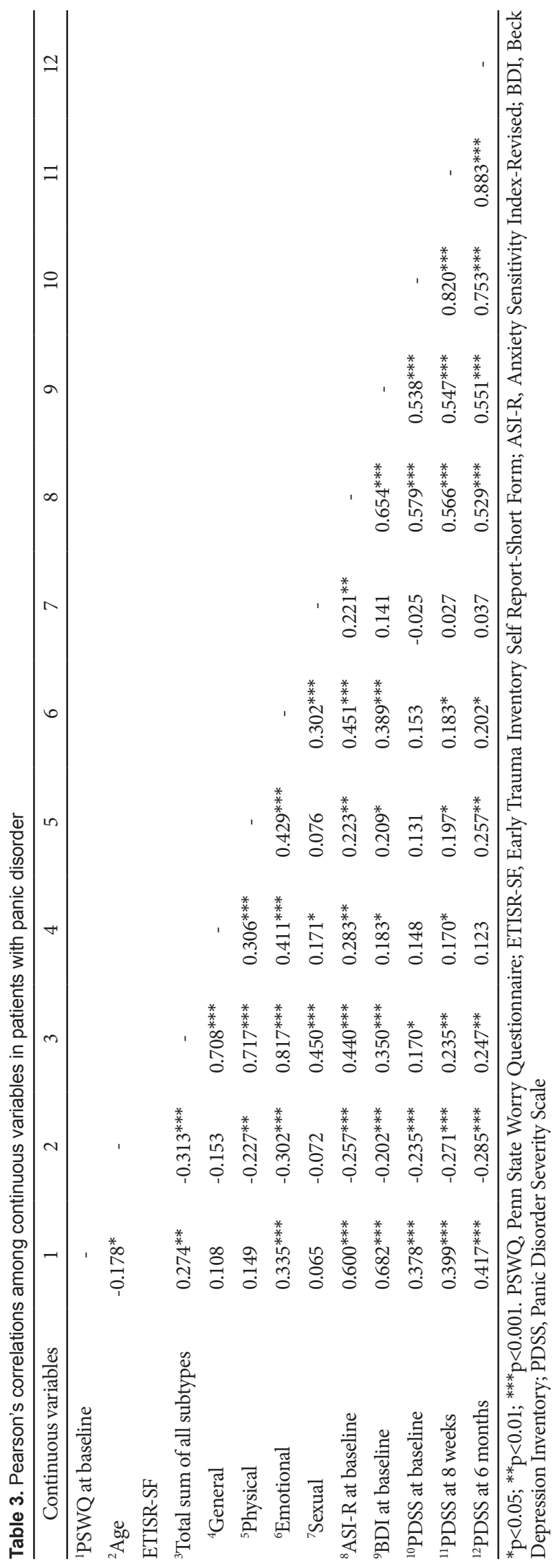

onset of disease in patients with PD..$^{52}$ In addition, one such study suggested that early physical or sexual trauma are risk factors related to increased frequency of panic attacks in patients with PD. ${ }^{52}$ Another study showed that a past history of early trauma was related to an earlier onset of symptoms in patients with PD. ${ }^{53}$ Although our findings showed that the early trauma is positively correlated with pathological worry in patients with PD, there was no significant direct association between early trauma and long-term PTR in PD.

Our findings showed that the higher the patient's income level, the better the long-term PTR. We assume that individuals with a higher level of income generally tend to show less symptoms and disability, resulting in better PTR after long-term follow-up, which is consistent with a previous study. ${ }^{54}$ However, our study findings showed that old age, gender, education level, and marital status are not significant potential sociodemographic predictors of long-term PTR. Therefore, further research on this is necessary in the future.

In addition, CBT effectively reduced pathological worries with a large overall effect size showing improvement following treatment at the 6-month follow-up in patients with GAD. ${ }^{55}$ According to Well's metacognitive model in GAD, negative beliefs about the uncontrollability, danger, and meaning of worry may cause patients to worry about worrying, which in turn intensifies anxiety symptoms. ${ }^{56}$ Further, changes in panic-related cognitions predicted the improvement of symptom severity for PD, mediating worry for CBT but not for pharmacotherapy. ${ }^{57}$ Therefore, patients with PD with pathological worries might experience more severe anxiety symptoms than PD patients without pathological worries, and this might also be related to PTR.

Our study has several limitations. First, it is believed that in addition to self-reported evaluation measures such as PSWQ, objective evaluation measures evaluated by clinicians are necessary. Second, recall bias can happen when evaluating early trauma. Third, we recruited patients with PD in an acute care hospital, some of which might have depressive episodes in the long-term follow-up, as happens in the natural course of PD. Therefore, the possibility cannot be ruled out that the sampling bias influenced the response to long-term pharmacological treatment.

In conclusion, the current findings suggest that the symptoms of pathological worries could be associated with poor long-term PTRs in patients with PD. Therefore, our study highlights the need to detect the symptoms of pathological worry early to determine the direction of medical treatment and predict the results of pharmacotherapy for patients with PD. The optimization of pharmacological treatments and CBT will be necessary for individuals with PD in the future. 
Table 4. Binary logistic regression results predicting the pharmacological treatment response at 6 months in patients with panic disorder

\begin{tabular}{|c|c|c|c|}
\hline \multirow{2}{*}{ Variables } & \multicolumn{3}{|c|}{ Pharmacological treatment response at 6 months } \\
\hline & $\mathrm{B}$ & p-value & Odds ratio $(95 \% \mathrm{CI})$ \\
\hline Age (years) & 0.018 & 0.467 & $1.018(0.970-1.069)$ \\
\hline Gender (male) & 0.582 & 0.267 & $1.789(0.641-4.996)$ \\
\hline Level of education (high school or less) & -0.381 & 0.495 & $0.683(0.229-2.041)$ \\
\hline Marital status (living without partner) & -0.815 & 0.150 & $0.443(0.146-1.344)$ \\
\hline Monthly income (below 1,800 \$USD) & 3.854 & $0.001^{* *}$ & $47.166(4.571-486.658)$ \\
\hline PSWQ at baseline (total sum) & -0.072 & $0.018^{*}$ & $0.930(0.876-0.988)$ \\
\hline BDI at baseline (total sum) & -0.089 & $0.047^{*}$ & $0.915(0.839-0.999)$ \\
\hline PDSS at baseline (total sum) & 0.284 & $<0.001^{* * *}$ & $1.329(1.158-1.524)$ \\
\hline ASI-R at baseline (total sum) & 0.017 & 0.283 & $1.017(0.986-1.050)$ \\
\hline Early trauma (ETISR-SF, total sum of all subtypes) & -0.068 & 0.346 & $0.934(0.810-1.076)$ \\
\hline$-2 \log$ likelihood & \multicolumn{3}{|c|}{108.163} \\
\hline$\chi^{2}(\mathrm{df})$ & \multicolumn{3}{|c|}{$43.959(10)\left(\mathrm{p}<0.001^{* * *}\right)$} \\
\hline Cox \& Snell R ${ }^{2}$ & \multicolumn{3}{|c|}{0.305} \\
\hline Overall percentage (\%) & \multicolumn{3}{|c|}{67.8} \\
\hline
\end{tabular}

Criteria for response of pharmacological treatment in patients with panic disorder is classified as the total PDSS score of $40 \%$ or greater reduction compared to the PDSS total score at baseline. ${ }^{*} \mathrm{p}<0.05 ;{ }^{* *} \mathrm{p}<0.01 ;{ }^{* *} \mathrm{p}<0.001$. CI, confidence interval; PSWQ, Penn State Worry Questionnaire; BDI, Beck Depression Inventory; PDSS, Panic Disorder Severity Scale; ASI-R, Anxiety Sensitivity Inventory-Revised; ETISRSF, Early Trauma Inventory Self Report-Short Form

\section{Availability of Data and Material}

The datasets generated or analyzed during the study are not publicly available because all participants did not consent their information exposure.

\section{Conflicts of Interest}

The authors have no potential conflicts of interest to disclose.

\section{Author Contributions}

Conceptualization: all authors. Data curation: all authors. Formal analysis: all authors. Funding acquisition: Sang-Hyuk Lee. Investigation: all authors. Methodology: all authors. Project administration: all authors. Resources: all authors. Software: all authors. Supervision: Sang-Hyuk Lee. Validation: all authors. Writing_original draft: all authors. Writing-review \& editing: all authors.

\section{ORCID iDs}

Hyun-Ju Kim

Ji Eun Kim

Sang-Hyuk Lee

https://orcid.org/0000-0002-8093-3366 https://orcid.org/0000-0003-0143-2633

https://orcid.org/0000-0001-9097-261X

\section{Funding Statement}

This work was supported by the Basic Science Research Program through the National Research Foundation of Korea which is funded by the Ministry of Education, Science and Technology, by the Ministry of Science and ICT of the Government of South Korea (2018-R1D1A1B07046978) and (NRF-2019M3C7A1032262) to S.H. Lee.

\section{Acknowledgments}

We thank all members of the Clinical Laboratory for Integrative studies in Mindfulness and Brain imaging for their kindness and its support.

\section{REFERENCES}

1. Borkovec TD, Robinson E, Pruzinsky T, DePree JA. Preliminary exploration of worry: some characteristics and processes. Behav Res Ther
1983;21:9-16.

2. Borkovec T, Ray WJ, Stober J. Worry: a cognitive phenomenon intimately linked to affective, physiological, and interpersonal behavioral processes. Cognit Ther Res 1998;22:561-576.

3. American Psychiatric Association. Diagnostic and Statistical Manual of Mental Disorders (DSM- $\left.5^{\circledR}\right)$. Washington DC: American Psychiatric Pub; 2013.

4. Hallion LS, Tolin DF, Assaf M, Goethe J, Diefenbach GJ. Cognitive control in generalized anxiety disorder: relation of inhibition impairments to worry and anxiety severity. Cognit Ther Res 2017;41:610-618.

5. Davey GC, Wells A. Worry and Its Psychological Disorders: Theory, Assessment and Treatment. England: John Wiley \& Sons Inc; 2006.

6. Yook K, Lee SH, Ryu M, Kim KH, Choi TK, Suh SY, et al. Usefulness of mindfulness-based cognitive therapy for treating insomnia in patients with anxiety disorders: a pilot study. J Nerv Ment Dis 2008;196: 501-503.

7. Aghighi A, Mohammadi N, Taghanaki CR, Imani M. Effectiveness of emotion regulation group therapy on symptom reduction, worry and emotion dysregulation in individuals with Panic disorder. JAC 2020; 10:65-88.

8. Vøllestad J, Sivertsen B, Nielsen GH. Mindfulness-based stress reduction for patients with anxiety disorders: evaluation in a randomized controlled trial. Behav Res Ther 2011;49:281-288.

9. Kim HS, Kim EJ. Effects of relaxation therapy on anxiety disorders: a systematic review and meta-analysis. Arch Psychiatr Nurs 2018;32:278284 .

10. Beheshti N, Zemestani M, Rezaei F. Comparing the effectiveness of cognitive behavioral therapy focused on intolerance of uncertainty and pharmacotherapy on worry, intolerance of uncertainty, and cognitive avoidance in patients with generalized anxiety disorder. Iran J Psychiatr Clin Psychol 2018;24:240-255.

11. Rodriguez BF, Weisberg RB, Pagano ME, Bruce SE, Spencer MA, Culpepper $\mathrm{L}$, et al. Characteristics and predictors of full and partial recovery from generalized anxiety disorder in primary care patients. J Nerv Ment Dis 2006;194:91-97. 
12. Perna G, Caldirola D. Management of treatment-resistant panic disorder. Curr Treat Options Psychiatry 2017;4:371-386.

13. Bandelow B, Rüther E. Treatment-resistant panic disorder. CNS Spectr 2004;9:725-739.

14. Bandelow B, Behnke K, Lenoir S, Hendriks G, Alkin T, Goebel C, et al. Sertraline versus paroxetine in the treatment of panic disorder: an acute, double-blind noninferiority comparison. J Clin Psychiatry 2004;65:405413.

15. Freire RC, Hallak JE, Crippa JA, Nardi AE. New treatment options for panic disorder: clinical trials from 2000 to 2010. Expert Opin Pharmacother 2011;12:1419-1428.

16. Albus M, Scheibe G, Scherer J. Panic disorder with or without concomitant depression 5 years after treatment: a prospective follow-up. J Affect Disord 1995;34:109-115.

17. Maier W, Buller R. One-year follow-up of panic disorder. Eur Arch Psychiatry Neurol Sci 1988;238:105-109.

18. Noyes Jr R, Garvey MJ, Cook BL. Follow-up study of patients with panic disorder and agoraphobia with panic attacks treated with tricyclic antidepressants. J Affect Disord 1989;16:249-257.

19. Noyes R, Reich J, Christiansen J, Suelzer M, Pfohl B, Coryell WA. Outcome of panic disorder: relationship to diagnostic subtypes and comorbidity. Arch Gen Psychiatry 1990;47:809-818.

20. Scheibe G, Albus M. Predictors and outcome in panic disorder: a 2-year prospective follow-up study. Psychopathology 1997;30:177-184.

21. Sharp D, Power K. Predicting treatment outcome for panic disorder and agoraphobia in primary care. Clin Psychol Psychother 1999;6:336-348.

22. Slaap BR, den Boer JA. The prediction of nonresponse to pharmacotherapy in panic disorder: a review. Depress Anxiety 2001;14:112-122.

23. Chavira DA, Stein MB, Golinelli D, Sherbourne CD, Craske MG, Sullivan $\mathrm{G}$, et al. Predictors of clinical improvement in a randomized effectiveness trial for primary care patients with panic disorder. J Nerv Ment Dis 2009;197:715-721.

24. Kim HJ, Song C, Bang M, Lee SH. Early sexual trauma is related with the tapetum in patients with panic disorder. J Affect Disord 2020;267: 107-113.

25. Hayasaka Y, Purgato M, Magni LR, Ogawa Y, Takeshima N, Cipriani A, et al. Dose equivalents of antidepressants: evidence-based recommendations from randomized controlled trials. J Affect Disord 2015; 180:179-184.

26. Gim M, Kim MK, Lee JH, Kim W, Moon E, Seo HJ, et al. Korean guidelines for the treatment of panic disorder 2018: Psychosocial Treatment Strategies. Anxiety Mood 2019;15:13-19.

27. Simon N, Hollander E, Rothbaum BO, Stein DJ. The American Psychiatric Association Publishing Textbook of Anxiety, Trauma, and OCDRelated Disorders (3rd edition ed). Washington, DC: American Psychiatric Pub; 2020.

28. Meyer TJ, Miller ML, Metzger RL, Borkovec TD. Development and validation of the penn state worry questionnaire. Behav Res Ther 1990; 28:487-495.

29. Lim YJ, Kim YH, Lee EH, Kwon SM. The Penn State worry questionnaire: psychometric properties of the Korean version. Depress Anxiety 2008;25:E97-E103.

30. Jeon JR, Lee EH, Lee SW, Jeong EG, Kim JH, Lee D, et al. The early trauma inventory self report-short form: psychometric properties of the Korean version. Psychiatry Investig 2012;9:229-235.

31. Lim YJ, Yu BH, Kim JH. Korean anxiety sensitivity index-revised: its factor structure, reliability, and validity in clinical and nonclinical samples. Depress Anxiety 2007;24:331-341.

32. Taylor S, Cox BJ. An expanded anxiety sensitivity index: evidence for a hierarchic structure in a clinical sample. J Anxiety Disord 1998;12:463483.

33. Shear MK, Brown TA, Barlow DH, Money R, Sholomskas DE, Woods SW, et al. Multicenter collaborative panic disorder severity scale. Am J Psychiatry 1997;154:1571-1575.

34. Beck AT, Steer RA, Brown GK. Beck Depression Inventory (BDI-II).
San Antonio: TX: Psychological Corp; 1996.

35. Barlow DH, Gorman JM, Shear MK, Woods SW. Cognitive-behavioral therapy, imipramine, or their combination for panic disorder: a randomized controlled trial. JAMA Psychiatry 2000;283:2529-2536.

36. Aaronson CJ, Shear MK, Goetz RR, Allen LB, Barlow DH, White KS, et al. Predictors and tie course of response among panic disorder patients treated with cognitive-behavioral therapy. J Clin Psychiatry 2008;69: 418-424.

37. Furukawa TA, Katherine Shear M, Barlow DH, Gorman JM, Woods SW, Money R, et al. Evidence-based guidelines for interpretation of the Panic Disorder Severity Scale. Depress Anxiety 2009;26:922-929.

38. Mohlman J, Price RB, Eldreth DA, Chazin D, Glover DM, Kates WR. The relation of worry to prefrontal cortex volume in older adults with and without generalized anxiety disorder. Psychiatry Res Neuroimaging 2009;173:121-127.

39. Beer JS, Knight RT, D’Esposito M. Controlling the integration of emotion and cognition: the role of frontal cortex in distinguishing helpful from hurtful emotional information. Psychol Sci 2006;17:448-453.

40. Roppongi T, Nakamura M, Asami T, Hayano F, Otsuka T, Uehara K, et al. Posterior orbitofrontal sulcogyral pattern associated with orbitofrontal cortex volume reduction and anxiety trait in panic disorder. Psychiatry Clin Neurosci 2010;64:318-326.

41. Sobanski T, Wagner G, Peikert G, Gruhn U, Schluttig K, Sauer H, et al. Temporal and right frontal lobe alterations in panic disorder: a quantitative volumetric and voxel-based morphometric MRI study. Psychol Med 2010;40:1879-1886.

42. Eysenck MW. Anxiety: The Cognitive Perspective. Brigton: Psychology Press; 2013.

43. Munjack DJ, Crocker B, Cabe D, Brown R, Usigli R, Zulueta A, et al. Alprazolam, propranolol, and placebo in the treatment of panic disorder and agoraphobia with panic attacks. J Clin Psychopharmacol 1989; 9:22-27.

44. Slaap BR, den Boer JA. The prediction of nonresponse to pharmacotherapy in panic disorder: a review. Depress Anxiety 2001;14:112-122.

45. Albus M, Scheibe G, Scherer J. Panic disorder with or without concomitant depression 5 years after treatment: a prospective follow-up. J Affect Disord 1995;34:109-115.

46. Kim B, Cho SJ, Lee KS, Lee JY, Choe AY, Lee JE, et al. Factors associated with treatment outcomes in mindfulness-based cognitive therapy for panic disorder. Yonsei Med J 2013;54:1454-1462.

47. Lesser IM, Rubin RT, Pecknold JC, Rifkin A, Swinson RP, Lydiard RB, et al. Secondary depression in panic disorder and agoraphobia: I. Frequency, severity, and response to treatment. Arch Gen Psychiatry 1988; 45:437-443.

48. Stewart SH, Taylor S, Jang KL, Cox BJ, Watt MC, Fedoroff IC, et al. Causal modeling of relations among learning history, anxiety sensitivity, and panic attacks. Behav Res Ther 2001;39:443-456.

49. McNally RJ. Anxiety sensitivity and panic disorder. Biol Psychiatry 2002; 52:938-946.

50. Kang EH, Kim B, Choe AY, Lee JY, Choi TK, Lee SH. Panic disorder and health-related quality of life: the predictive roles of anxiety sensitivity and trait anxiety. Psychiatry Res 2015;225:157-163.

51. Khanipour H. Thought control strategies and trait anxiety: predictors of pathological worry in non-clinical sample. Int J Behav Sci 2011;5: 173-178.

52. Goodwin RD, Fergusson DM, Horwood LJ. Childhood abuse and familial violence and the risk of panic attacks and panic disorder in young adulthood. Psychol Med 2005;35:881-890.

53. Kipper L, Blaya C, Wachleski C, Dornelles M, Salum GA, Heldt E, et al. Trauma and defense style as response predictors of pharmacological treatment in panic patients. Eur Psychiatry 2007;22:87-91.

54. Roy-Byrne P, Sherbourne C, Miranda J, Stein M, Craske M, Golinelli $\mathrm{D}$, et al. Poverty and response to treatment among panic disorder patients in primary care. Am J Psychiatry 2006;163:1419-1425.

55. Covin R, Ouimet AJ, Seeds PM, Dozois DJ. A meta-analysis of CBT 
Pathological Worry and Treatment Response in PD

for pathological worry among clients with GAD. J Affect Disord 2008; 22:108-116.

56. Wells A. Meta-cognition and worry: a cognitive model of generalized anxiety disorder. Behav Cogn Psychother 1995;23:301-320.
57. Meuret AE, Rosenfield D, Seidel A, Bhaskara L, Hofmann SG. Respiratory and cognitive mediators of treatment change in panic disorder: evidence for intervention specificity. J Consult Clin Psychol 2010;78: 691-704. 